\title{
Marketing Intelligence dalam Menumbuhkan Jiwa Entrepreneur pada Generasi Milenial
}

\author{
Abdul Waris ${ }^{1 *}$, Wahyu Setiyorini ${ }^{2}$, Chodidjah ${ }^{2}$ \\ ${ }^{1}$ Jurusan Administrasi Niaga, Politeknik Negeri Malang, Indonesia \\ ${ }^{2}$ Fakultas Ekonomi dan Bisnis, Universitas Merdeka Malang, Indonesia \\ *waris_sip@polinema.ac.id
}

\begin{abstract}
Indonesia is currently coming into a demographic dividend era occuring due to changes in the age structure of its population because the proportion of productive age is above 2/3 of the total population and around $50.36 \%$ of the population of productive age are basically millennial generation. This is an opportunity that must be utilized as well as possible by maximizing the capabilities of the current millennial generations which have open, free, critical, and courageous mindset as the essential things in entrepreneurship. The aim of this research is to find out the effect of marketing intelligence in growing the entrepreneurial spirit in millennial generations by using quantitative approaches and descriptive analysis method. The results show that: 1) marketing intelligence activities performed by millennial generation can help growing the entrepreneurial spirit; and 2) marketing research has the dominant influence of the growing entrepreneurial spirit of the millennial generation in marketing intelligence activities. This marketing intelligence activity does not have to be done in a group, but it can be done independently or alone.
\end{abstract}

Keywords : Entrepreneurial Spirit, Millenial Generations, Marketing Intelligence

\section{PENDAHULUAN}

Indonesia saat ini memasuki era baru yang lebih dikenal dengan era bonus demografi, ini merupakan fenomena yang sangat langka karena dalam perjalanan sejarah suatu Negara hal ini hanya akan terjadi satu kali saja. Salah satu tanda bahwa era bonus demografi ini telah tiba di Indonesia adalah terjadinya kenaikan jumlah populasi penduduk yang produktif (berusia antara 15 tahun s.d. 65 tahun) secara signifikan jika dibandingkan dengan populasi penduduk yang non produktif (yang saat ini berusia dibawah 15 tahun dan berusia 65 tahun ke atas), rasio populasi penduduk yang produktif saat ini di Indonesia mencapai $(2 / 3)$ dua sepertiga dari total penduduk yang ada atau yang biasa dikenal dengan istilah rasio ketergantungan (dependency rasio).

Era bonus demografi ini merupakan tantangan bagi Indonesia dan harus dijadikan sebuah peluang yang tidak boleh dilewatkan begitu saja, Indonesia harus mampu memanfaatkan potensi penduduk usia produktif yang cukup tinggi ini, apalagi berdasarkan data (Badan Pusat Statistik, 2018) menyebutkan bahwa ada sekitar $50,36 \%$ dari total penduduk yang berusia produktif merupakan gerenasi milenial. Dan berdasarkan teori generasi yang dikemukakan oleh (Mannheim, 1952) menyatakan bahwa generasi yang lahir antara tahun 1980-an sampai 2000-an dikategorikan sebagai gerenasi milenial. 
Di Indonesia para generasi milenial memiliki kesempatan serta peluang yang baik untuk berinovasi dengan dukungan ekosistem digital yang sedang tumbuh dan berkembang, seperti hadirnya bisnis e-commerce yang merupakan karya asli anak bangsa mampu memfasilitasi gerenasi milenial yang memiliki semangat untuk berwirausaha juga dapat berkembang. Selain bisnis e-commerce hadir pula bisnis yang bergerak di bidang transportasi online semisal transportasi online Gojek, Grab, Uber dan masih banyak lagi yang lainnya. Lahirnya bisnis e-commerce dan transportasi online ini merupakan hasil inovasi untuk menjawab tantangan dan kebutuhan dalam mewujudkan kemandirian secara ekonomi bagi generasi milenial di era digital ini.

Menurut Sebastian dkk. (2016), menyebutkan bahwa generasi milenial memiliki keunggulan yang tidak dimiliki oleh generasi sebelumnya, diantaranya adalah dalam melaksanakan segala aktifitas maupun kegiatannya generasi milenial menginginkan segala sesuatunya dilakukan serba cepat, sulit bertahan dalam pekerjaan yang sama dalam waktu yang relatif lama, sangat dinamis, kreatif, inovatif, sangat friendly dengan media sosial dan perkembangan teknologi.

Dunia industri saat ini jika ingin menjangkau segmen generasi milenial harus mulai meningkatkan cara-cara mereka dari sebelumnya, mengingat generasi milenial telah mampu merubah cara berpikir sebagai seorang konsumen yang lebih mengutamakan sisi emosi, keinginan, kebutuhan, dan tuntutannya. Maka dunia industri harus mampu mendeteksi perubahan cara berpikir tersebut.

Untuk mendeteksi orientasi perilaku konsumen yang efektif maka diperlukan kecerdasan bermarketing atau yang dikenal dengan marketing intelligence, hal ini diperlukan dalam bentuk pengumpulan data dan kemampuan analisis sebagai upaya dalam pengambilan keputusan yang tepat, seperti menganalisis tentang kondisi pesaing, daya saing produk serta memiliki kemampuan untuk memahami pasar dan pelanggan secara menyeluruh. Kemampuan ini akan berjalan secara optimal apabila dilaksanakan oleh orang yang mengerti tentang teknologi seperti generasi milenial. Dengan kemampuan dibidang teknologi yang melekat dalam diri generasi milenial saat ini juga dapat menjadi modal membuka kesempatan dan peluang untuk berinovasi dalam berbagai bidang (berwirausaha).

Hal ini sejalan dengan hasil penelitian Ambarwati \& Sobari (2020), yang menyatakan bahwa mahasiswa dapat menjadi seorang pengusaha apabila mampu mengubah pola pikir konvensional ke digital dengan memanfaatkan teknologi yang terus berkembang dimulai dari hal yang sederhana seperti membangun pemasaran melalui media social yang dimiliki, bahkan saat ini ada mahasiswa yang mampu menciptakan aplikasi untuk membangun bisnisnya sendiri.

Li (2006) dalam penelitiannya juga memperoleh hal serupa, yakni $68,4 \%$ atau lebih dari dua pertiga dari mahasiswa yang diwawancarainnya, mereka lebih memilih untuk mempunyai bisnis sendiri dari pada bekerja kepada orang lain, artinya bahwa semangat untuk berwirausaha dikalangan mahasiswa itu sangat tinggi.

Berdasar uraian tersebut, penelitian ini akan mengkaji bagaimana peran marketing intelligence dalam menumbuhkan jiwa entrepreneur generasi milenial.

\section{Marketing Intelligence}

Marketing intelligence (kecerdasan pemasaran) merupakan manifestasi dari sebuah kemampuan dalam mengumpulakn dan menganalisis suatu informasi atau data agar segala sesuatu yang terkait dengan pengambilan keputusan dapat diansipasi dengan baik, terdapat empat bagian yang dibutuhkan dalam kecerdasan ini meliputi product intelligence, competitor intelligence, customer understanding and market understanding (Kurniawan, 2020).

Menurut Burns dkk., (2017) terdapat dua unsur penting dalam marketing intelligence yaitu meliputi marketing research dan customer relationship marketing/database marketing, yang menjadi fokus dari marketing research adalah lebih 
kepada proses perencanaan pemasaran yang dimulai dengan menganalisis situasi dan kondisi serta membangun strategi dan program pemasaran yang diakhiri dengan mengaplikasikan strategi dan program yang sudah di rancang sebelumnya. Sedangkan yang menjadi fokus utama dari database marketing terletak pada pengolahan data dalam sisten database. Cara kerja database marketing ini adalah dengan mengkolaborasikan antara teori pemasaran dengan teori teknologi informasi dan database marketing ini masih tergolong teori yang masih baru (Guoxiang \& Zhiheng, 2013).

Dalam strategi pemasaran modern seringkali mengunakan database marketing ini untuk aktifitas data mining, aktifitas ini dilakukan untuk mendukung dalam pengambilan keputusan guna mempermudah dalam menemukan pengetahuan baru (Luo dkk., 2012). Menariknya dalam aktifitas database marketing ini memanfaatkan teknologi yang ada mulai dari proses pengumpulan data sampai dengan analisis datanya. Salah satu teknik analisis yang bisa digunakan adalah SaaS (Software as a Service) atau juga bisa mengunakan OLAP (Online Analitycal Processing) dan masih banyak lagi tools yang bisa digunakan. Output dari data mining ini sangat penting karena nantinya akan digunakan sebagai dasar dalam pengambilan sebuah keputusan seperti untuk menganalisis target penjualan, membuat forcasting konsumen serta untuk menganalisis pelanggan yang potensial.

Berdasarkan hasil penelitian

Amborowati \& Suyanto (2015) menyatakan bahwa memanfaatkan teknologi data mining bisa menjadi salah satu opsi yang dapat digunakan dalam melakukan segmentasi pasar/konsumen potensial untuk mendukung kegiatan marketing intelligence.

Menurut Kottler \& Armstrong (2008), marketing intelligence adalah kumpulan informasi dan analisis secara sistematis terkait informasi yang tersedia tentang pesaing dan perkembangan di pasar.

\section{Jiwa Entrepreneur}

Entrepreneurship selalu berkembang dari generasi ke generasi mengikuti perkembangan zaman, namun ada hal yang tidak akan pernah berubah yaitu kemampuan seorang entrepreneur yang selalu dapat memanfaatkan sumber daya yang ada untuk selalu mengahasilkan produk/jasa yang baru, menciptakan bisnis yang baru atau bahkan mengembangkan bisnis yang sudah ada (Usman dalam Hatta, 2008).

Menciptakan nilai tambah dengan memakai cara baru dan berbeda dari sebelumnya merupakan point inti dalam kewirausahaan agar dapat bersaing secara kompetitif dengan para pesainya. Menurut Zimmerer dalam Hatta (2008), terdapat beberapa pendekatan metode dalam penciptaan nilai tambah diantaranya adalah melalui proses penemuan pengetahuan yang baru atau bisa juga memberikan nilai tambah dengan mengembangkan teknologi yang baru atau bisa juga dengan cara memperbaiki produk atau layanan jasa yang sudah ada saat ini atau bahwakan dapat menemukan cara yang lebih efisien dengan sumber daya yang lebih sedikit.

Setiap orang pada hakekatnya memiliki semangat entrepreneur dalam dirinya, asalkan orang tersebut memiliki kemauan untuk senantiasa berperilaku kreatif, inovatif, selalu siap menghsdapi perubahan dan tantangan serta menyukai kemajuan karena sejatinya rahasia untuk menjadi seorang entrepreneur adalah kreatif dan inovatif.

Menurut Li (2006) dari hasil
penelitian yang pernah dilakukan
memberikan kesimpulan bahwa Perguruan
Tinggi memiliki tanggungjawab untuk ikut
serta menumbuhkan potensi-potensi yang
dimiliki oleh peserta didiknya dengan
memberikan pendidikan dan wawasan terkait
kewirausahaan karena dengan memahami
secara detail tentang kewirausahaan ternyata
dapat mempengaruhi minat kaum muda untuk
menjadi seorang wirausahawan.




\section{Generasi Milenial}

Dalam generation theory yang dikemukakan oleh Mannheim (1952) menyebut generasi milenial dengan istilah generasi Y, jika berdasarkan dari karakteriktik tahun kelahirannya generasi $\mathrm{Y}$ ini adalah generasi yang lahir dalam rasio tahun 1980-an sampai tahun 2000-an, dan melalui editorial dalam sebuah surat kabar utama yang terbit di Amerika Serikat tahun 1993 berperan sangat besar dalam mempopulerkan istilah ini.

Carlson (2008) menyatakan hal yang sama dengan Mannheim terkait dengan karakteristik generasi milenial berdasarkan tahu lahirnya, Carlson menyebutkan periode tahun 1983 sampai tahun 2001 merupakan rentang tahun kelahiran para generasi milenial. Sedangkan Howe \& Strauss (2000) memberikan ilustrasi terkait dengan generasi milenial adalah mereka yang lahir pada tahun 1982 sudah mulai masuk prasekolah dan mereka yang pada tahun 2000 lulus dari Sekolah Menengah Atas (SMA) dan istilah ini mulai populer pada tahun 1987.

Hasil penelitian dari Lancaster \& Stillman (2003) menghasilkan karakteristik yang melekat dalam diri generasi milenial, Lancaster \& Stillman menyatakan bahwa generasi milenial memiliki sikap yang realistis, sangat menghormati perbedaan yang ada, lebih senang bekerjasama dalam tim serta memiliki sikap optimis dan percaya diri yang tinggi dalam setiap hal yang dilakukan dan ternyata generasi milenial memiliki kepercayaan terhadap nilai-nilai moral dan sosial, namun sangat pragmatis dalam menyelesaikan masalah.

Sedangkan berdasarkan hasil penelitian Hidayatullah dkk. (2018) dengan judul perilaku generasi milenial dalam mengunakan aplikasi go-food menyatakan bahwa salah satu karakterikstik generasi milenial yang berpengaruh secara signifikan adalah kemampuan generasi milenial dalam memanfaatkan teknologi dan informasi dalam setiap aktifitas yang dilakukan sehari-hari dimulai dari mereka bangun tidur sampai kembali tidur. Disamping itu untuk menjamin kepuasan kelompok generasi milenial, informasi yang disajikan harus yang berkualitas (no hoax) dengan tampilan informasi yang menarik (Hidayatullah dkk., 2020).

Berikut ini adalah hipotesis yang digunakan :

$\mathrm{H}_{1}$ : Marketing research berpengaruh positif dalam menumbuhkan jiwa entrepreneur pada generasi milenial

$\mathrm{H}_{2}$ : Database marketing berpengaruh positif dalam menumbuhkan jiwa entrepreneur pada generasi milenial

$\mathrm{H}_{3}$ : Marketing research berpengaruh dominan dalam menumbuhkan jiwa entrepreneur pada generasi milenial

\section{METODE}

Pendekatan metode yang digunakan adalah deskriftif kuantitatif, yaitu untuk menganalisis dan mengetahui bagaimana peran marketing intelligence dalam menumbuhkan jiwa entrepreneur pada generasi milenial saat ini. Pendekatan ini akan berupaya untuk mengkaji dan mengurai keterkaitan antar variabel yang digunakan dalam penelitian dengan menggunakan tools descriptive analysis dan multiple linear regression analysis.

Penelitian ini mengunakan lokus Perguruan Tinggi yang berada di Kota Malang dengan jumlah 150 mahasiswa sebagai sampel yang tersebar di seluruh Perguruan Tinggi di Kota Malang dengan mengunakan google form, sedangkan pengambilan sampelnya mengunakan teknik multistage random sampling.

Instrumen yang digunakan ini sudah melalui uji kelayakan mengunakan uji validitas dan reliabilitas dengan merujuk pada pendapat Sugiono P.D, (2011) yang mengatakan bawa apabila ingin mengetahui sejauh mana instrument yang digunakan dapat mengukur sesuatu yang seharusnya diukur maka dapat mengunakan uji validitas. Dari semua item (24) yang telah di uji menggunakan uji validitas, menyatakan bahwan semua item dalam kuesioner adalah valid karena nilai probabilitas yang dimiliki lebih kecil dari pada 0,05. Sedangkan uji reliabilitas jika merujuk pada pendapat 
Nurgiyantoro \& Gunawan (2000) yang mengatakan bahwa nilai koefisien 0,60 menjadi syarat minimum sebuah instrument akan dinyatakan reliable. Dari semua variabel yang telah di uji mengunakan uji reliabilitas telah dinyatakan reliable. Sehingga instrument dinyatakan layak untuk digunakan.

\section{HASIL DAN PEMBAHASAN Deskripsi Responden}

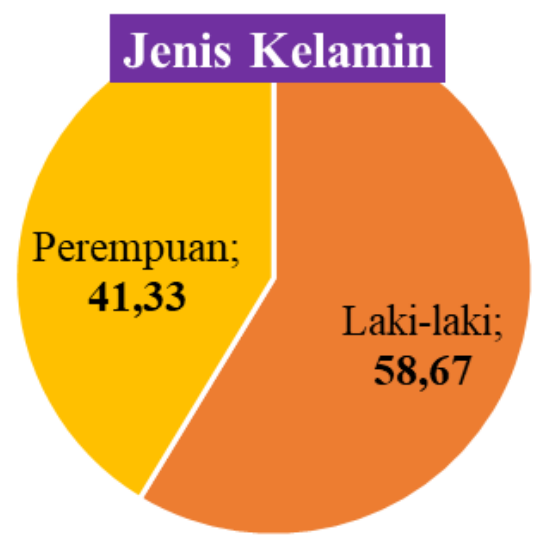

Gambar 1 : Jesnis Kelamin Responden Sumber: data primer (diolah), 2020

Responden dalam penelitian marketing intelligence dalam menumbuhkan jiwa entrepreneur pada generasi milenial yang dilakukan di Kota Malang ini didominasi oleh responden yang berjenis kelamin laki-laki sebanyak 58,67\%, sedangkan sisanya adalah responden perempuan yang sebanyak $41,33 \%$ responden.

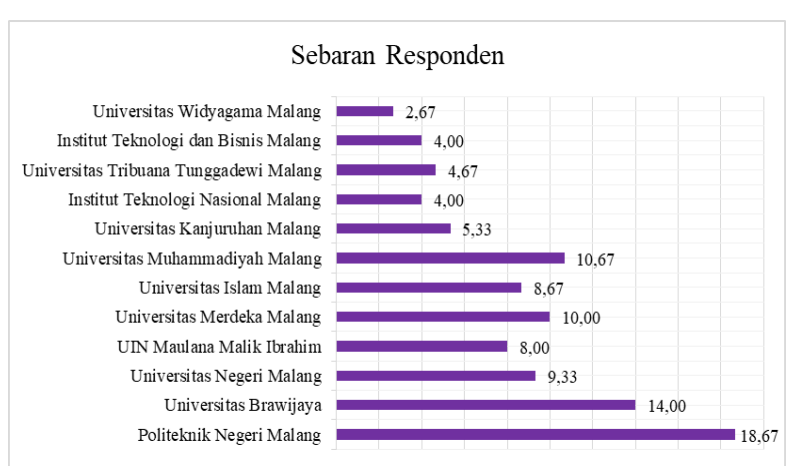

Gambar 2 : Deskripsi Responden Berdasarkan sebaran di Perguruan Tinggi

Sumber: data primer (diolah), 2020
Untuk sebaran responden berdasarkan Perguruan Tingginya, maka sebaran responden tertinggi untuk penelitian marketing intelligence dalam menumbuhkan jiwa entrepreneur pada generasi milenial yang dilakukan di Kota Malang berada di Politeknik Negeri Malang dengan jumlah sebarannya sebanyak $18,67 \%$, kemudian sebaran terbanyak berikutnya berada di Universitas Brawijaya sebanya $14,00 \%$, sedangkan sebaran responden yang paling sedikit berada di Universitas Widyagama Malang yaitu sebanyak 2,67\%. Dari sebaran responden menunjukkan bahwa sebagian besar berada di Politeknik Negeri Malang.

\section{Marketing Research}

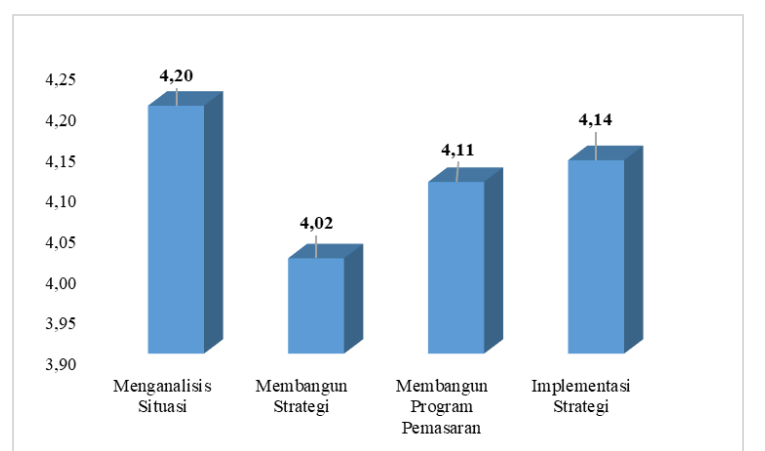

Gambar 3 : Deskripsi Marketing Research berdasarkan Indikatornya

Sumber: data primer (diolah), 2020

Nilai rata-rata untuk indikator marketing research dalam penelitian marketing intelligence dalam menumbuhkan jiwa entrepreneur pada generasi milenial yang dilakukan di Kota Malang adalah sebesar 4,12. Nilai ini memberi gambaran bahwa pada saat responden menerapkan prinsip marketing intelligence yang dalam hal ini adalah marketing research dapat membantu dalam menumbuhkan jiwa entrepreneur mereka, hal ini dikarenakan responden akan mendapatkan informasi tentang gambaran situasi pasar sehingga dapat membagun strategi dan program pemasaran yang cocok untuk diimplementasikan dalam memasarakan produknya kepada konsumennya maupun calon konsumennya. Kegiatan marketing research dapat dilakukan secara tim maupun seorang diri hal ini 
tergantung tingkat kebutuhan dan biaya yang dimilikinya.

\section{Database Marketing}

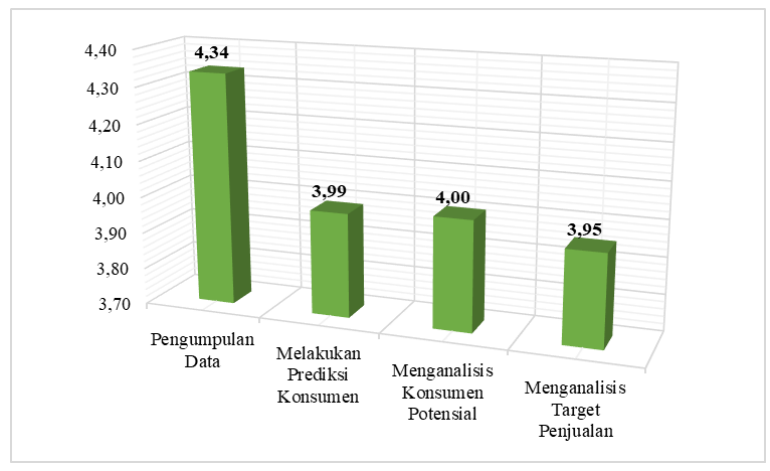

Gambar 4 : Deskripsi Database Marketing berdasarkan Indikatornya

Sumber: data primer (diolah), 2020

Nilai rata-rata untuk indikator database marketing dalam penelitian marketing intelligence dalam menumbuhkan jiwa entrepreneur pada generasi milenial yang dilakukan di Kota Malang adalah sebesar 4,07. Nilai ini memberi gambaran bahwa pada saat responden menerapkan prinsip marketing intelligence yang dalam hal ini adalah database marketing dapat membantu dalam menumbuhkan jiwa entrepreneur-nya, karena setelah responden melakukan pengumpulan data melalui marketing research, maka data tersebut akan dijadikan dasar dalam melakukan prediksi tentang prilaku konsumen sehingga nantinya hal tersebut akan menjadi dasar untuk menganalisis konsumen yang potensial terhadap produk atau jasa yang akan dilakukan, selain untuk memperoleh konsumen potensial. Hal ini juga dilakukan untuk menganalisis target penjualan dimasa yang akan datang. Database marketing ini menjadi sangat penting sebagai dasar dalam pengambilan keputusan, dan kegiatan database marketing dapat memanfaatkan aplikasi dan teknologi yang ada saat ini, diantaranya adalah SaaS (Software as a Service) atau OLAP (Online Analytical Processing) dll.

\section{Menumbuhkan Jiwa Entrepreneur}

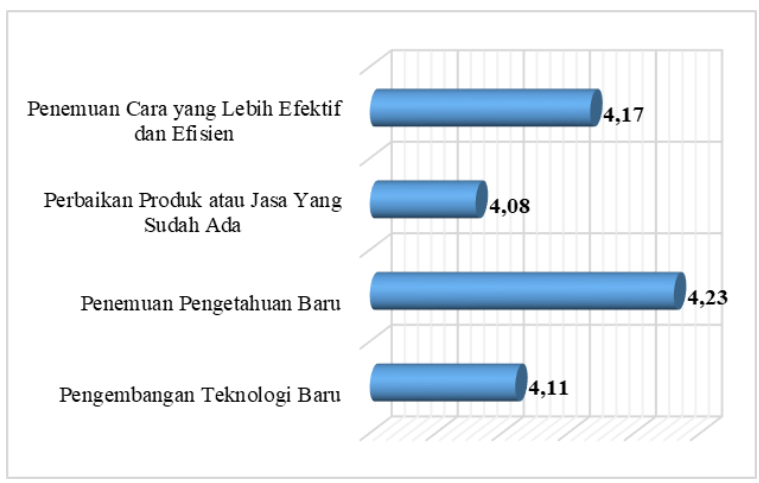

Gambar 5 : Deskripsi dalam Menumbuhkan Jiwa Entrepreneur berdasarkan Indikatornya Sumber: data primer (diolah), 2020

Nilai rata-rata untuk indikator upaya dalam menumbuhkan jiwa entrepreneur dalam penelitian marketing intelligence dalam menumbuhkan jiwa entrepreneur pada generasi milenial yang dilakukan di Kota Malang adalah sebesar 4,15. Nilai ini memberi gambaran bahwa responden dalam penelitian ini dapat menumbuhkan jiwa entrepreneur mereka bisa melalui berbagai cara diantaranya adalah dengan mengembangkan teknologi yang sudah ada saat ini, kadangkala jiwa entrepreneur mereka tumbuh karena mereka mendapatkan pengetahuan yang baru tentang entrepreneurship di bangku perkuliahan, sehingga apabila responden telah melakukan aktifitas marketing intelligence yang terdiri dari marketing research dan database marketing akan menjadi bekal yang sangat berarti bagi responden untuk memulai usahanya atau bisa juga digunakan untuk memperbaiki layanan jasa ataupun produk yang sudah ada dengan memberikan terobosan-terobosan yang baru sehingga dapat menghemat waktu dan biaya. Namun tumbuh dan berkembangnya jiwa entrepreneur seseorang bisa datang dari mana saja baik faktor internal maupun eksternal dari yang bersangkutan 


\section{Uji Asumsi Klasik Multikolinieritas}

Tabel 1. Uji Multikolinieritas

\begin{tabular}{lccc}
\hline \multicolumn{1}{c}{ Variable } & VIF & Hasil & Keterangan \\
\hline $\begin{array}{l}\text { Marketing } \\
\text { research }\left(\mathrm{X}_{1}\right)\end{array}$ & 1,852 & $<10$ & $\begin{array}{c}\text { Tidak terjadi } \\
\text { multikolinieritas }\end{array}$ \\
$\begin{array}{l}\text { Database } \\
\text { marketing }\left(\mathrm{X}_{2}\right)\end{array}$ & 1,852 & $<10$ & $\begin{array}{c}\text { Tidak terjadi } \\
\text { multikolinieritas }\end{array}$ \\
\hline
\end{tabular}

Sumber: data primer (diolah), 2020

Dalam regresi linier berganda diketahui tidak terjadi gejala multikolinieritas setalah dilakukan uji multikolinieritas seperti yang terdapat pada tabel 1 di atas.

\section{Uji Asumsi Klasik Heterokedastisitas}

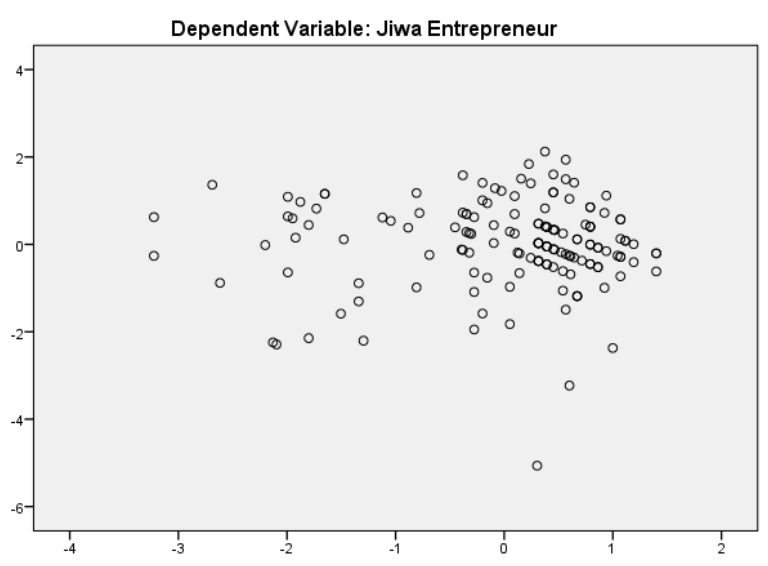

Gambar 6 : Uji Heterokedastisitas

Sumber: data primer (diolah), 2020

Uji heterokedastisitas pada gambar 6 di atas menunjukkan jika data observasi yang digunakan tidak terjadi problem heterokedastisitas karena penyebaran titiktitik yang ada menyebar secara sempurna baik diatas maupun di bawah sumbu Y serta pola penyebaranya tidak teratur.

\section{Uji Asumsi Klasik Autokorelasi}

\section{Metode Durbin Waston (DW)}

digunakan untuk menguji ada tidaknya gejala autokorelasi dengan mengunakan rumus: $\mathrm{du}<\mathrm{DW}<(4-\mathrm{du})$. Dengan mengunakan pendekatan Durbin Waston (DW) ini diperoleh bahwa dalam model regresi yang digunakan bebas dari gejala autokorelasi dengan nilai : $1,760<1,927<2,240$.

\section{Uji Asumsi Klasik Normalitas}

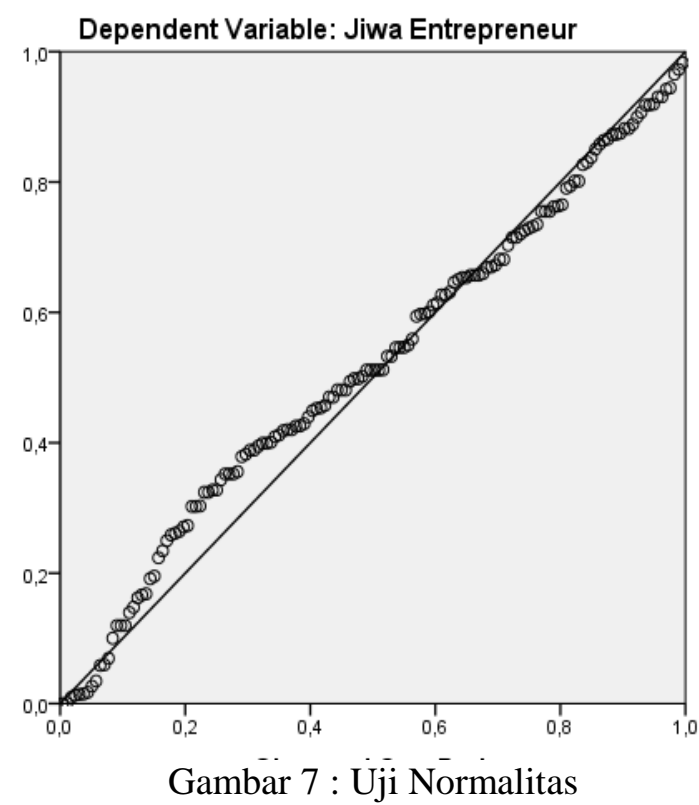

Sumber: data primer (diolah), 2020

Data dalam penelitian ini berdistribusi secara normal, hal ini dapat dilihat dari norma probability plots dimana titik-titik tersebut mengikuti garis diagonal yang terdapat pada garis kurva normal pada gambar 7 di atas.

\section{Analisis Regresi Linier Berganda}

Tabel 2. Rekapitulasi Hasil Analisis Regresi Linier Berganda

\begin{tabular}{|c|c|c|c|c|c|}
\hline \multirow{2}{*}{ Variabel } & \multirow{2}{*}{ Keterangan } & \multicolumn{2}{|c|}{ Koefisien Regresi } & \multirow{2}{*}{$\mathrm{t}_{\text {hitung }}$} & \multirow{2}{*}{ Sig. } \\
\hline & & $\mathrm{B}$ & $\beta$ & & \\
\hline $\mathrm{X}_{1}$ & $\begin{array}{l}\text { Marketing } \\
\text { research }\end{array}$ & 0,469 & 0,565 & 7,127 & 0,000 \\
\hline $\mathrm{X}_{2}$ & $\begin{array}{l}\text { Database } \\
\text { marketing }\end{array}$ & 0,174 & 0,191 & 2,417 & 0,017 \\
\hline \multicolumn{2}{|c|}{ Konstanta } & \multicolumn{4}{|l|}{1,511} \\
\hline \multicolumn{2}{|l|}{$\mathrm{R}^{2}$} & \multicolumn{4}{|l|}{0,495} \\
\hline \multicolumn{2}{|l|}{$F_{\text {hitung }}$} & \multicolumn{4}{|l|}{74,086} \\
\hline \multicolumn{2}{|l|}{ Sig. F } & \multicolumn{4}{|l|}{0} \\
\hline \multicolumn{2}{|l|}{$\mathrm{N}$} & \multicolumn{4}{|l|}{150} \\
\hline \multicolumn{2}{|l|}{$\mathrm{Y}$} & \multicolumn{4}{|c|}{ Jiwa entrepreneur } \\
\hline \multicolumn{2}{|l|}{$\mathrm{T}_{\text {tabel }}$} & \multicolumn{4}{|l|}{1,976} \\
\hline \multicolumn{2}{|l|}{$\mathrm{F}_{\text {tabel }}$} & \multicolumn{4}{|l|}{3,06} \\
\hline
\end{tabular}

Sumber: data primer (diolah), 2020

Persamaan regresi linier berganda yang diperoleh adalah $\mathrm{Y}=1,511+0,469 \mathrm{X}_{1}+$ $0,174 X_{2}$ dengan nilai $\mathrm{R}$ Square-nya (koefisien determinasi) dalam penelitian ini sebesar 
0,495. Ini memberikan pengertian bahwa pada saat variabel independennya yang terdiri dari marketing research $\left(\mathrm{X}_{1}\right)$ dan database marketing $\left(\mathrm{X}_{2}\right)$ jika bersamaan akan mampu memberikan kontribusi dalam menumbuhkan jiwa entrepreneur pada generasi milenial dengan nilai 49,5\%, sehingga dapat dikatakan bahwa kontribusi ini berada dalam kategori sedang.

\section{Uji Kelayakan Model}

Uji $\mathrm{F}$ dalam penelitian ini digunakan untuk menagalisis uji model dengan menggukanan nilai standar probabilitas di bawah 0,05. Dari hasil uji F yang dilakukan maka diperoleh nilai probabilitasnya sebasesar 0,000 sehingga diperoleh perbandingan $(0,000<0,05)$, dengan demikian maka model regresi linier yang diestimasi layak untuk digunakan karena derajat signifikansi yang ditentukan lebih besar dari nilai probabilitas yang diperoleh.

\section{Pengujian Hipotesis}

Uji T dalam penelitian ini digunakan untuk melakukan pengujian hipotesis dengan mengunakan nilai probabilitas di bawah 0,05 , uji t ini untuk mengetahui apakah terdapat pengaruh yang signifikan atau tidak dari independent variable terhadap dependent variable.

Output uji t yang terdapat pada tabel 2 dapat dilihat bahwa marketing research memiliki pengaruh positif dan pengaruhnya signifikan dalam menumbuhkan jiwa entrepreneur di kalangan generasi milenial. Oleh karena itu, maka hipotesis yang pertama teruji atau dapat diterima karena nilai probabilitas dari marketing research adalah sebesar $0,000 \quad(<0,05)$ dari nilai yang ditentukan. Hasil ini tidak dapat dipisahkan dari kemampuan responden yang dalam hal ini adalah generasi milenial dalam melakukan aktivitas marketing research karena mereka adalah geranasi yang sangat fleksibel dan melek teknologi informasi, dimana mereka dengan kemampuan fleksibelitasnya tersebut dapat dengan mudah melakukan marketing research secara mandiri untuk mendapatkan informasi tentang gambaran situasi pasar yang nantinya akan dijadikan dasar untuk membagun strategi dan program pemasaran yang cocok untuk diimplementasikan dalam kegiatan memasarkan produk atau jasanya kepada konsumennya maupun calon konsumennya, sehingga akan mampu bersaing secara kompetitif dengan para pesaingnya. Hal ini akan menjadi stimulus yang luar biasa bagi generasi milenial untuk berani dalam berwirausaha, karena dengan bekal informasi dan data yang diperoleh dari proses marketing research yang dilakukan akan menjadi bekal untuk memberikan kepercayaan diri yang tinggi bagi generasi milenial dalam berwirausaha.

Pada tabel 2 dapat diketehui bahwa uji t untuk variabel database marketing memiliki pengaruh positif dan pengaruhnya signifikan dalam menumbuhkan jiwa entrepreneur di kalangan generasi milenial. Oleh karena itu, maka hipotesis yang kedua teruji atau dapat diterima karena nilai probabilitas dari database marketing sebesar 0,017 $(<0,05)$ dari nilai yang ditentukan. Hasil ini tidak dapat dipisahkan dari kemampuan responden yang merupakan generasi milenial dalam melakukan aktivitas database marketing, dimana mereka tumbuh dan berkembang dalam ekosistem digital yang sangat friendly dengan perkembangan teknologi informasi membuat para generasi milenial menjadi lebih kreatif dan dinamis dalam melakukan aktivitas database marketing, sehingga data/informasi yang sudah terkumpul dapat dijadikan dasar menganalisis konsumen yang potensial untuk mencapai target penjualan dan memenangkan persaingan dimasa yang akan datang.

Berdasarkan nilai koefisien beta $(\beta)$ dapat diketahui bahawa variabel yang paling dominan pengaruhnya dalam menumbuhkan jiwa entrepreneur pada generasi milenial adalah variabel marketing research dibandingkan dengan variabel database marketing. Oleh karena itu, maka hipotesis yang ketiga dalam penelitian ini teruji atau dapat diterima karena marketing research memiliki nilai koefisien beta $(\beta)$ paling tinggi sebesar 0,565 jika dibandingkan dengan nilai koefisien beta $(\beta)$ database marketing yang 
hanya memiliki nilai sebesar 0,191 . Selain itu argumentasi yang mendasari marketing research dapat berpengaruh dominan dalam menumbuhkan jiwa entrepreneur pada generasi milenial ini tidak terlepas dari tingkat urgensi dari marketing research dalam aktifitas marketing intelligence karena marketing research merupakan langkah awal dalam rangkaian marketing intelligence berupa pengumpulan informasi dan data yang valid dengan cara yang sistematis, kreatif dan inovatif, karena informasi dan data yang diperoleh ini nantinya akan dijadikan dasar analisa untuk menetukan strategi dan program dalam rangka memenangkan persaingan dalam bidang usahanya.

\section{Kesimpulan}

Berikut ini adalah kesimpulan yang diperoleh dari hasil analisa: 1) marketing research memiliki pengaruh yang signifikan dan pengaruh tersebut positif dalam menumbuhkan jiwa entrepreneur pada generasi milenial; 2) database marketing memiliki pengaruh yang signifikan dan pengaruh tersebut positif dalam menumbuhkan jiwa entrepreneur pada generasi milenial; dan 3) faktor utama bagi generasi milenial dalam menumbuhkan jiwa entrepreneur-nya adalah aktivitas marketing research. Sampai saat ini masih tidak banyak para generasi milenial maupun pengusaha menegah kebawah yang melakukan marketing intelligence baik pada saat memulai usaha maupun untuk mengembangkan usahanya, padahal aktifitas marketing intelligence ini dapat dilakukan secara mandiri (sendiri) sehingga biaya yang dibutuhkan relatif kecil.

\section{DAFTAR PUSTAKA}

Ambarwati, A., \& Sobari, I. S. (2020). Membangun Jiwa Kewirausahaan Di Era Milenial Bagi ahasiswa Institut Stiami Kampus Tangerang Selatan. Jurnal Komunitas: Jurnal Pengabdian Kepada Masyarakat, 2(2), 140-144. https://doi.org/10.31334/jks.v2i2.736 Amborowati, A., \& Suyanto, M. (2015). Studi
Dukungan Marketing Intelligence Pada Strategi Pemasaran Seminar Nasional Informatika (SEMNASIF). http://jurnal.upnyk.ac.id/index.php/sem nasif/article/view/1365

Badan Pusat Statistik. (2018). Statistik Gender Tematik: Profil Generasi Milenial Indonesia. Kementerian Pemberdayaan Perempuan dan Perlindungan Anak.

Burns, A. C., Veeck, A., \& Bush, R. F. (2017). Marketing Research (Ninth edit). New York : Pearson Education.

Carlson, E. (2008). Who are the Lucky Few? In The Lucky Few (pp. 1-10). Springer. https://link.springer.com/chapter/10.100 7\%2F978-1-4020-8541-3_1

Guoxiang, L., \& Zhiheng, Q. (2013). Data Mining Applications in Marketing Strategy. 2013 Third International Conference on Intelligent System Design and Engineering Applications, 518-520. https://doi.org/10.1109/ISDEA.2012.12 6

Hatta, G. (2008). Pedoman Manajemen Kesehatan di sarana pelayanan kesehatan. Revisi, Jakarta Universitas Indonesia.

Hidayatullah, S., Rachmawati, I. K., Aristanto, E., Waris, A., \& Patalo, R. G. (2020). Peran Sistem Informasi Pemasaran, Kualitas Pelayanan dan Entrepreneurial marketing serta Kepuasan Terhadap Loyalitas Generasi Milenial Berkunjung ke Tempat Wisata. Jurnal Ilmiah Bisnis dan Ekonomi Asia, 14(1), 74-83. https://jurnal.stie.asia.ac.id/index.php/ji beka/article/view/184

Hidayatullah, S., Waris, A., Devianti, R. C., Sari, S. R., Wibowo, I. A., \& PW, P. M. (2018). Perilaku Generasi Milenial dalam Menggunakan Aplikasi Go-Food. Jurnal Manajemen dan Kewirausahaan, 6(2), 240-249. https://doi.org/10.26905/jmdk.v6i2.256 0

Howe, N., \& Strauss, W. (2000). Millennials rising: The next great generation. Vintage. 
Kurniawan V. (2020). Definisi dan Sistem Kerja Marketing Intelligence | BINUS UNIVERSITY BANDUNG - Kampus Teknologi Kreatif. https://binus.ac.id/bandung/2020/04/def inisi-dan-sistem-kerja-marketingintelligence/

Kottler, P., \& Armstrong, G. (2008). PrinsipPrinsip Pemasaran. Ed. 12, Jilid 1. Jakarta: Erlangga.

Lancaster, L. C., \& Stillman, D. (2003). When generations collide: Who they are, why they clash, how to solve the generational puzzle at work. HarperBusiness New York,

NY. https://pdfs.semanticscholar.org/bd24/8f 640f066d6a81b470f93aa3fe49295c852 b.pdf

Li, W. (2006). Entrepreneurial Intention Among International Students: Testing a Model of entrepreneurial intention. Paper Presented at the USASBE Small Business Advancent National Center.

Luo, Y., Cai, Q. R., Xi, H. X., Liu, Y. J., \& $\mathrm{Yu}$, Z. M. (2012). Telecom Customer Segmentation With K-means Clustering. ICCSE 2012 - Proceedings of 2012 7th International Conference on Computer Science and Education. https://doi.org/10.1109/ICCSE.2012.62 95158

Mannheim, K. (1952). The Sociological Problem of Generation. Essays on the Sociology of Knowledge.

Nurgiyantoro, B., \& Gunawan, M. (2000). Statistik Terapan untuk Ilmu-Ilmu Sosial. Gadjah Mada University Press, Yogyakarta.

Sebastian, Y., Amran, D., \& Lab, Y. (2016). Generasi Langgas Millenials Indonesia. Gagas Media.

Sugiono P.D. (2011). Metode Penelitian Pendidikan (pendekatan kuwantitatif, kuwalitatif, $R \& D)$ ). In Alfabbeta Pres. 